\title{
Preliminary evaluation of piezoelectric sensors for the prediction of compression failure of brick masonry components
}

\author{
C. Cuadra, N. Shimoi, T. Sasaki \& T. Taguchi \\ Akita Prefectural University, Japan
}

\begin{abstract}
Applicability of a piezoelectric bolt-type sensor to detect or predict compression failure of masonry specimens is investigated in this paper. Originally, masonry specimens were constructed to investigate the influence of the type of bond on compression strength. Flemish bond style and English bond style were selected in the present study and 3 specimens for each bond style were constructed. Flemish bond style specimens show slightly lower strength in comparison to English bond style specimens. In 4 of these specimens, piezoelectric bolt-type sensors were installed and signal responses were observed at different stages of compression tests. It is believed that these responses correspond to different levels of cracking and the most important is the signal observed just before crushing since this response could be used for collapse prevention in case of actual structure.

Keywords: masonry, compression test, Young modulus, piezoelectric sensor.
\end{abstract}

\section{Introduction}

In Japan some historical masonry structures still remain and efforts are done to preserve them. Analytical estimation of their dynamic characteristics depends on accurate determination of their mechanical properties in especial elastic modulus [1-3]. Then as a first step, in this research the influence of the type of bonds on the elastic properties of brick masonry and on their maximum strength are investigated experimentally. For this purpose English bond style and Flemish bond style were chosen and 3 specimens of each type were constructed to be subjected to compression load. Since during compression test crushing failure is observed at the end of test $[4,5]$, piezoelectric bolt-type sensors were installed in 4 specimens to try to predict the occurrence of that failure. 
In the case of masonry properties, slight difference was observed for ultimate strength between Flemish bond type specimen and English bond type specimen. It is believed that lower strength of Flemish bond type specimen is due to larger volume of mortar used in this type of bond. Since strength of mortar presents lower values than brick units it is reasonable that combination of bricks of larger strength with cement mortar of lower strength produce specimens of lower strength when larger volume of mortar is used.

\section{Characteristics of piezoelectric bolt-type sensor}

The piezoelectric bolt sensor is shown in Figure 1, and consist of a piezoelctric cable covered by an envelope of urethane resin. In a previous research Shimoi et al. [6] investigated the chracteristics of a new type of bolt sensor, however in that case the nominal diameter of the bolt was $20 \mathrm{~mm}$. Then in this research the diameter of the bolt was reduced to $10 \mathrm{~mm}$ to produce a minor disturbance in the structure where the bolt must be installed.

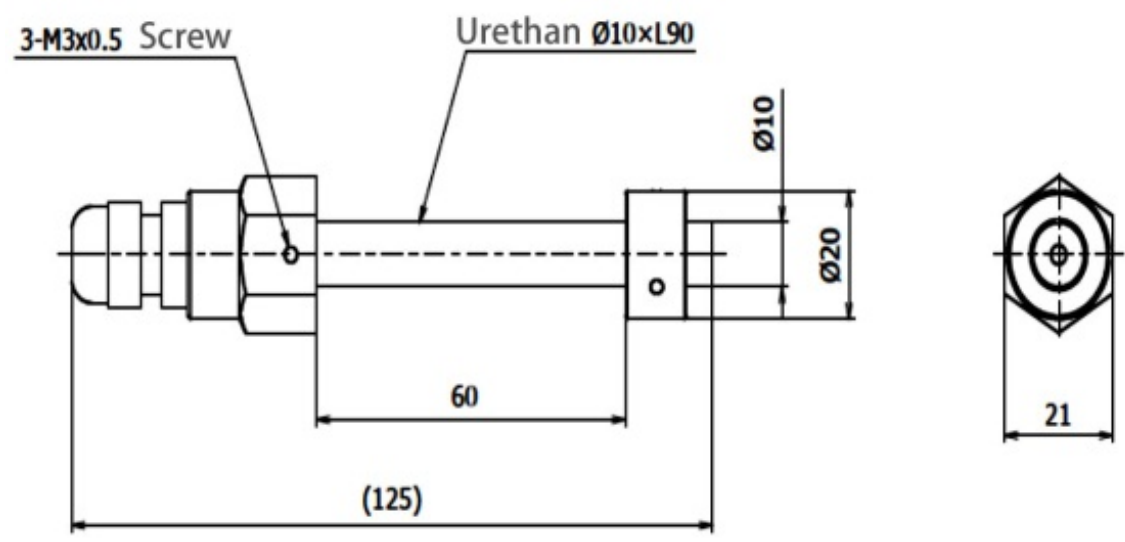

Figure 1: Piezoelectric bolt-type sensor.

The structure of the inner piezoelectric cable is shown in Figure 2. The piezoelectric film which acts as electric condensor emits voltage when the cable is subjected to an external action that produces deformation on the cable, especially in case of dynamic action or vibration. This cable is connected to a computer board by means of a coneccion cable and the signal can be recorded directly by a computer for its posterior analysis. In this research, the sensors are used for static test to try to detect cracking instant since it is considered that cracking during compressioin test produces a sudden change in stress state which can be detected by proposed sensor. The sensor itself does not need input energy to emit its response. Moreover, the characteristics of the sensor like sampling frequency permits to send the signal to a four channels computer board for automatic data acquisition. In this way signals from four sensors can be recorded simultaneously with a direct input computer board. 


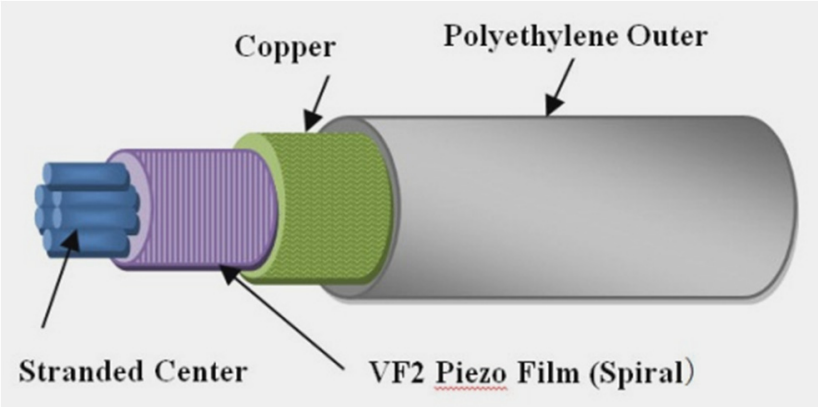

Figure 2: $\quad$ Structure of the inner piezoelectric cable.

Figure 3 shows the general scheme of the data acquisition system using the proposed bolt sensor. Data is recorded using a wireless system (Zigbee wireless module). Source energy (lithium battery pack Lipo2000mAh) is required for the board that receives the signal from the sensor and transmits it to the computer for data acquisition. Personal computer requires its own source of energy for acquisition and posterior data processing. Recording directly to the computer could permit to connect it to remote computers and then monitoring structures in real time from different location could be possible.

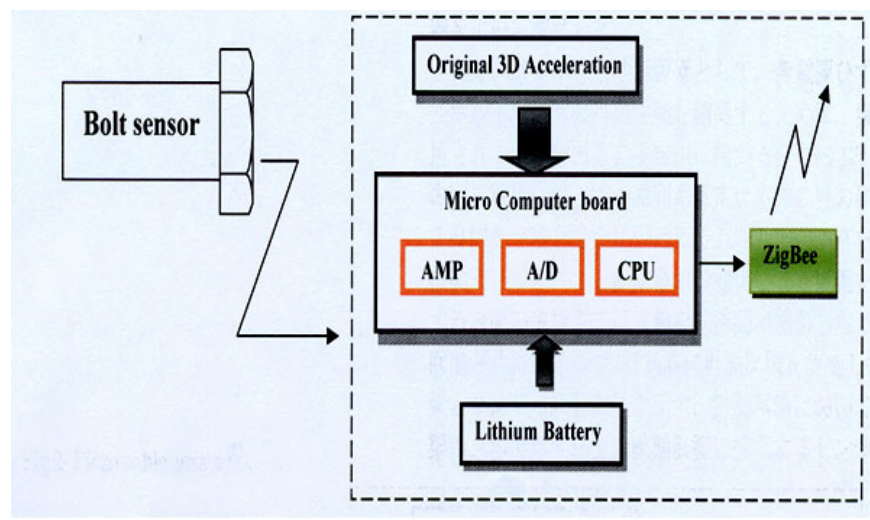

Figure 3: Scheme of data acquisition system.

\section{Compression tests}

Dimension of test specimens can be observed in Figure 4. Brick units were commercial bricks that are usually sold at supermarkets or DIY stores. The mortar was cement sand mortar whit a ratio of 1 to 4 ; that is 1 part of cement for 4 parts of sand. The thickness of mortar was $1 \mathrm{~cm}$. Nominal dimensions of specimens were $41 \mathrm{~cm}$ of height, $49 \mathrm{~cm}$ of width and $21 \mathrm{~cm}$ of thickness. For each bond type 3 specimens were constructed and they were called BF-1, BF-2 and BF-3 for Flemish bond; and BU-1, BU-2 and BU-3 for English type bond. 


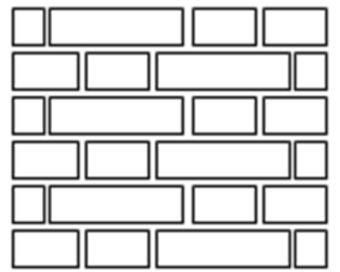

Flemish bond (BF)

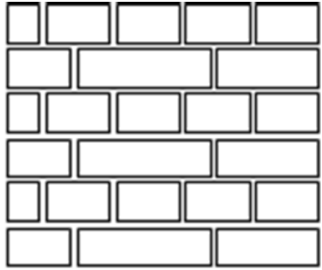

English bond (BU)
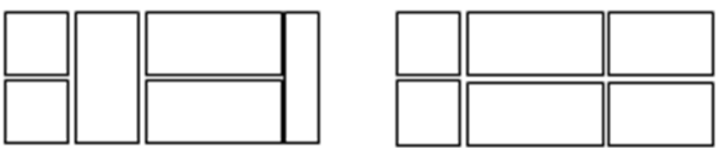

Odd layers $1,3,5$
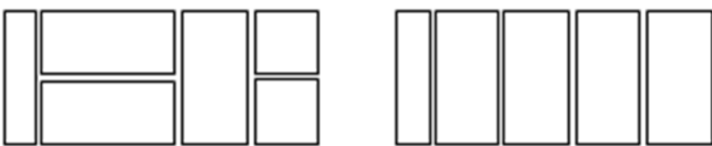

Even layers 2, 4,6

Figure 4: Test specimens.

Tests were performed at structural testing laboratory of Akita Prefectural University using a compression machine with $5000 \mathrm{kN}$ of capacity. Load was applied according to Japanese Industrial Standard (JIS) with a load stress velocity between 5 and $10 \mathrm{~N} / \mathrm{cm} 2 / \mathrm{s}$. Figure 5 shows compression test setup with piezoelectric sensors installed in test specimen. Considering specimen as a wall sensors were installed at out-of-plane direction and at in-plane direction.

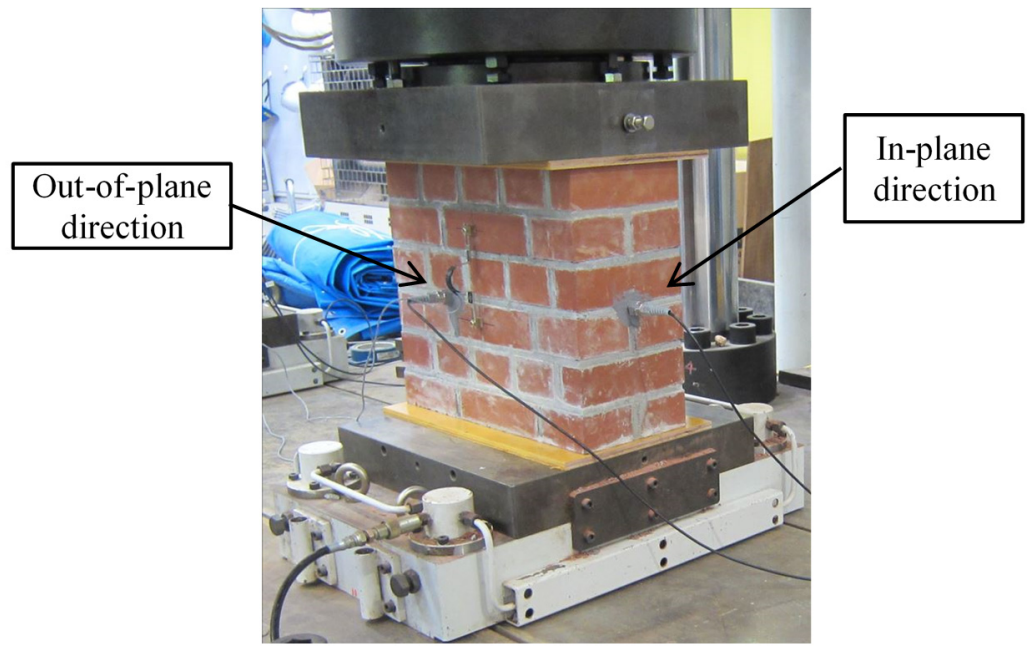

Figure 5: Piezoelectric sensors and test setup. 


\section{Tests results}

Test results are presented in Table 1 and it can be observed that Flemish bond type specimen has a lower strength than English bond type specimen. It is believed that lower strength of Flemish bond type specimen is due to larger volume of mortar used in this type of bond. Since strength of mortar presents lower values than brick units it is reasonable that combination of bricks of larger strength with cement mortar of lower strength produce specimens of lower strength when larger volume of mortar is used. On the other hand, portions of vertical joints that passes all layers presents larger volume for Flemish type specimens and it is believed that these joints have great influence on failure pattern.

Table 1: Compression test results.

\begin{tabular}{|c|c|c|c|}
\hline Specimen & $\begin{array}{c}\text { Maximum } \\
\text { load }(\mathrm{kN})\end{array}$ & $\begin{array}{c}\text { Strength } \\
\left(\mathrm{N} / \mathrm{mm}^{2}\right)\end{array}$ & \multirow{2}{*}{$\begin{array}{c}\text { Average } \\
\text { strength } \\
\left(\mathrm{N} / \mathrm{mm}^{2}\right)\end{array}$} \\
\hline BF-1 & 4129 & 40.37 & \multirow{2}{*}{41.18} \\
\hline BF-2 & 4154 & 40.45 & \multirow{2}{*}{4} \\
\hline BF-3 & 4378 & 42.72 & \multirow{2}{*}{42.24} \\
\hline BU-1 & 4288 & 41.67 & \\
\hline BU-2 & 4250 & 41.39 & \\
\hline BU-3 & 4466 & 43.67 & \\
\hline
\end{tabular}

Table 2 shows elastic Young modulus obtained from measurements using displacement transducers located on two faces of wall specimen. Results show higher values for Flemish bond specimens. However it is necessary to verify these results in future research since lower strength specimens give high elastic modulus which is contradictory. Rightest column of Table 2 shows estimated values of elastic modulus using a well-known relationship that states that Young modulus is 500 times the strength of masonry. Estimated values show good agreement only for Flemish bond specimen.

Table 2: Young modulus.

\begin{tabular}{|c|c|c|c|}
\hline Specimen & $\begin{array}{c}\text { Young modulus } \\
\left(\mathrm{N} / \mathrm{mm}^{2}\right)\end{array}$ & $\begin{array}{c}\text { Average } \\
\left(\mathrm{N} / \mathrm{mm}^{2}\right)\end{array}$ & $\begin{array}{c}\text { Estimated } \\
\left(\mathrm{N} / \mathrm{mm}^{2}\right)\end{array}$ \\
\cline { 1 - 2 } BF-1 & 23722 & \multirow{2}{*}{21529} & \multirow{2}{*}{20590} \\
\hline BF-2 & 19901 & & \\
\cline { 1 - 2 } BF-3 & 20964 & \multirow{2}{*}{17674} & 21120 \\
\cline { 1 - 2 } BU-1 & 16942 & & \\
\hline BU-2 & 17206 & \\
\hline BU-3 & 18875 &
\end{tabular}


Originally, the proposed piezoelectric sensors were designed for vibration measurements since piezoelectric material reacts only when some instantaneous change in stress condition occurs which is the case of dynamic loads. During compression test, static load is applied to specimens and slow changes are not detected by piezoelectric sensors. Then instantaneous responses of piezoelectric sensors are originated by sudden changes of stress condition (dynamic change) which corresponds to development of cracks. Results for bolt-type piezoelectric sensor are presented in Figures 6-9. Horizontal axis represents the time of compression test, and in vertical axis sensor response and load are plotted for comparison. Response of sensors can be divided into 3 zones. Zone (1) represents the first response at approximately $1 / 3$ of maximum load and it is believed that could be the response to first cracking of test specimen since sensor only responds to a sudden change in stress condition. Then zone (2) which is the response of sensor just before crashing or failure of specimen when cracks propagate extensively in specimen. And finally zone (3) which corresponds to the collapse or crushing of test specimen. Figures 6 and 7 are results for Flemish bond type specimens and Figures 8 and 9 are results for English bond type specimens.
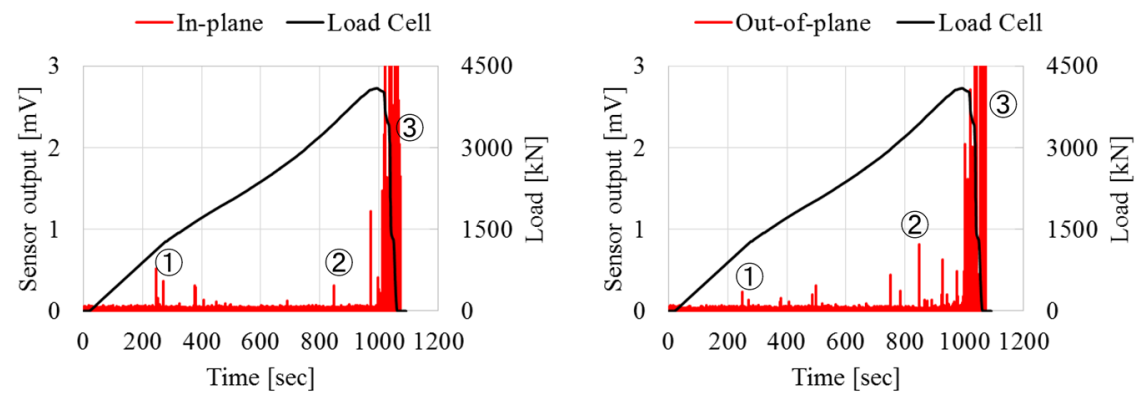

Figure 6: Sensor response and load for Flemish bond specimen BF-1.
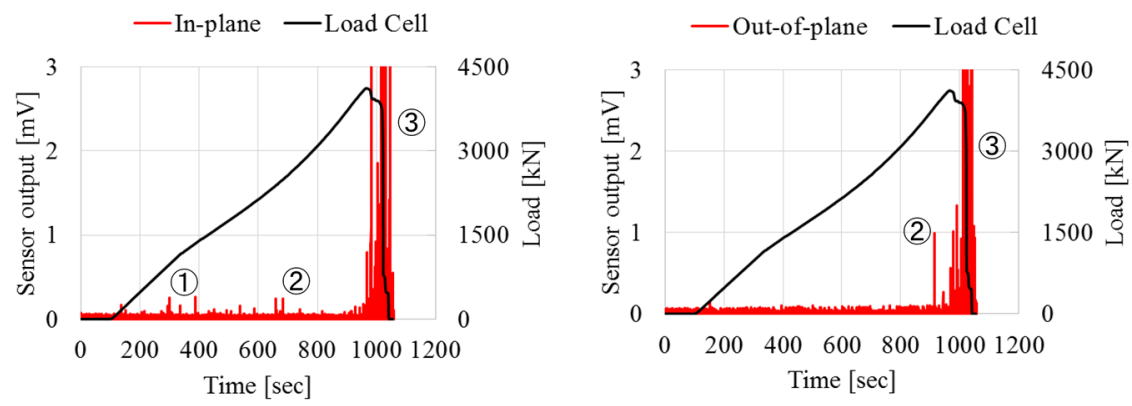

Figure 7: Sensor response and load for Flemish bond specimen BF-2. 

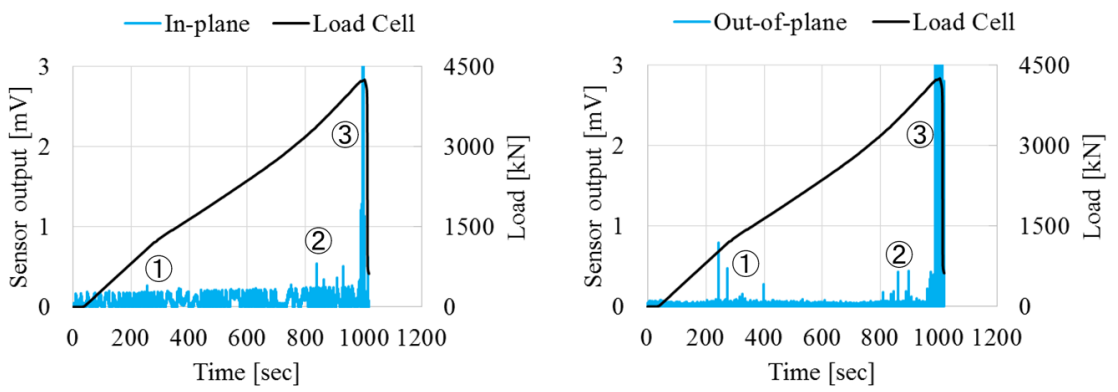

Figure 8: $\quad$ Sensor response and load for English bond specimen BU-1.
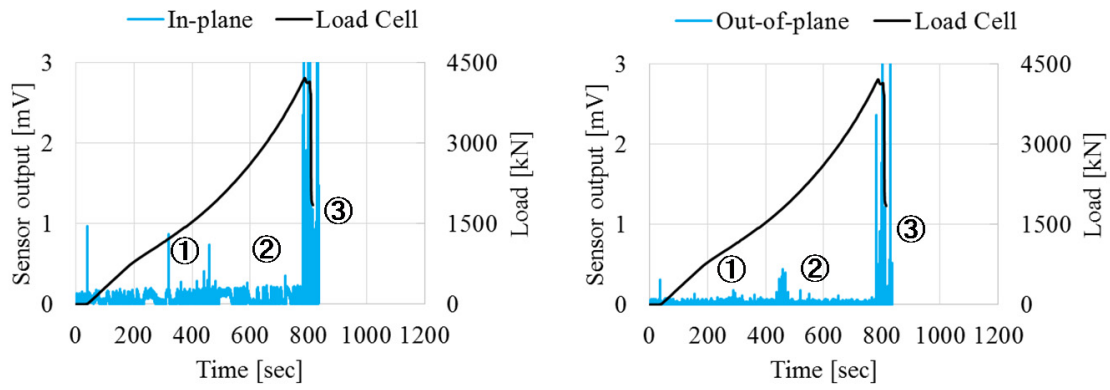

Figure 9: $\quad$ Sensor response and load for English bond specimen BU-2.

Examples of final condition of specimens after compression tests are shown in Figure 10. Crushing failure occurred at side with large amount of vertical joints near specimen end. In all cases crashing of specimens were detected by piezoelectric sensors (zone (3) therefore these sensor could be used for failure detection of structures. Signals of zones (1) and (2) are premonitory signals that is they are signals before failure. These premonitory signals could be used for failure prevention and damages mitigation that occurs in case of earthquakes $[7,8]$.

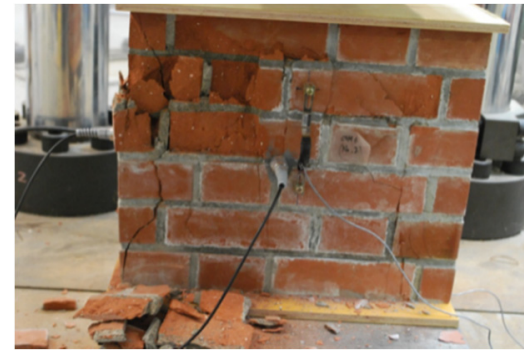

(a)

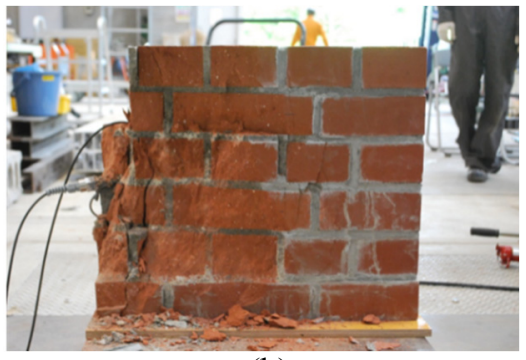

(b)

Figure 10: Final condition of specimens after compression tests. (a) Flemish bond-type specimen, (b) English bond-type specimen. 


\section{Conclusions}

Applicability of a piezoelectric bolt sensor to detect different stages of damage or failure during compression test of masonry specimens was investigated. Originally, two types of masonry bonds (English bond and Flemish bond) were used to investigate their influence on mechanical properties of brick masonry.

Premonitory signals and signals during crushing that were emitted by sensors could permit their use for structural health monitoring, failure prevention and damage mitigation.

With respect to masonry characteristics it can be stated that larger volume of bond mortar in French bond type specimen produces lower strength in comparison to English style bond since mortar have lower resistance than brick units. On the other hand Flemish style bond produces larger volume of vertical bond mortar that crosses the total height of specimens conducing to a failure at lower strength.

\section{References}

[1] Cuadra, C. H., Fujisawa, W. \& Saito, T., Collapse simulation of unreinforced masonry walls, Proceedings of the 15th World Conference on Earthquake Engineering, September 24-28, 2012, Lisbon, Portugal, Paper No. 1292.

[2] Kanai, J., Tokeshi, K., Cuadra, C., \& Karkee, M.B., Vibration characteristics of buildings using microtremor measurements. First European Conference on Earthquake Engineering and Seismology, Geneva, Switzerland, 3-8 September 2006, Paper Number: 708.

[3] Cuadra, C., Sato, Y., Tokeshi, J., Kanno, H., Ogawa, J., Karkee, M. B., \& Rojas, J., Evaluation of the dynamic characteristics of typical Inca heritage structures in Machupicchu. Ninth International Conference on Structural Studies, Repairs and Maintenance of Heritage Architecture, STREMAH IX, Malta, Jun. 2005, pp. 237-244.

[4] Peruvian Ministry of Construction, Masonry Code. Technical Code E070 for Masonry Constructions in Peru, 2006 (in Spanish).

[5] Peruvian Ministry of Construction, Adobe Code. Technical Code E080 for Adobe Masonry Constructions in Peru, 2006 (in Spanish).

[6] Shimoi, N., Cuadra, C., Madokoro, H. \& Saijo, M., Simple Smart Piezoelectric Bolt Sensor for Structural Monitoring of Bridges, International Journal of Instrumentation Science, Vol. 1, No. 5, 2012, pp. 78-83. doi: 10.5923/j.instrument.20120105.03.

[7] Cuadra, C. and Tokeshi, J. Lessons learned from the 2007 Pisco earthquake (Peru) and recommendations for disaster mitigation. Proceedings of the $14^{\text {th }}$ World Conference on Earthquake Engineering, October 12-17, 2008, Beijing, China.

[8] Cuadra, C., Saito, T., \& Zavala, C., Diagnosis for Seismic Vulnerability Evaluation of Historical Buildings in Lima, Peru, Journal of Disaster Research, JDR Vol. 8 No. 2 Mar. 2013, Special Issue on Enhancement of Earthquake and Tsunami Disaster Mitigation Technology in Peru, pp. 320327. 